\title{
EBSD Investigations on Cutting Edges of Non-Oriented Electrical Steel
}

\author{
Henrike M.S. Harstick ${ }^{1}$, Martin Ritter ${ }^{2}$ and Werner Riehemann ${ }^{3}$ \\ 1. Volkswagen AG, D 38436 Wolfsburg, Germany \\ 2. Technische Universität Hamburg-Harburg, Eißendorfer Straße 42, D 21073 Hamburg, Germany \\ 3. Technische Universität Clausthal, Agricolastraße 2, D 38678 Clausthal-Zellerfeld, Germany
}

In order to reduce the eddy current losses in electrical machines the stator and rotor cores are made up of stacked steel sheets. At present the sheet thickness of electrical steel for automotive applications is between $0.2 \mathrm{~mm}$ and $0.35 \mathrm{~mm}$. The material properties of the electrical steel sheets affect the performance and efficiency of an electrical machine [1]. Especially the mean grain size and the crystallographic texture have a strong influence on the magnetic properties of electrical steels. [2-3]. The entire manufacturing process, from the electrical steel coil to a stator and rotor package, affects the properties of the sheet material [4]. For high-volume productions of rotor and stator laminations the electrical sheets are cut in a stamping process. For small quantities this is not an economical process, thus a laser cutting process is frequently used. Both manufacturing methods, stamping and laser cutting, lead to local changes of the microstructure and related changes of the magnetic properties in the area of the cutting edge [5-8].

In this contribution only the cutting process will be considered. It is well known that the punching process has an influence on the magnetic properties of electrical steels [6-8]. With regard of highvolume productions, the influence of tool wear on the magnetic properties of electrical steels is an important topic. As a result of increasing tool wear, the plastic deformations caused by the shearing procedure during the punching process become stronger. Furthermore, tool wear causes an increase of the burr height which is an important characteristic value concerning the stacking process. A large burr height leads to short circuiting between electrical sheet layers and cause a corresponding increase in eddy current losses [9].

The magnetic properties of electrical steel are connected with its microstructure [3;10]. For the microstructural investigation of areas near the cutting edges, EBSD (electron backscatter diffraction) analysis is the method of choice because it achieves the required angular and spatial resolution. In order to estimate the influence of tool wear on electrical steel sheets, samples that were cut with various grades of tool wear have been investigated (see figure 1). The geometry and size of the affected zone as well as the magnitude of deformation in the material was determined in order to understand the material behavior with respect to cutting parameters and tool wear.

\section{References:}

[1] Lim et al, 2nd EDPC, Nürnberg, Germany (2012), p.276-278.

[2] M.F. de Campos, J.C. Teixeira, F.J.G. Landgraf, J. Magn. Magn. Mater. 301 (2006), p. 94-99.

[3] D.S. Petroviĉ, B. Markoli, M. Ceh, J. Magn. Magn. Mater. 322 (2010), p. 3041-3048.

[4] A.P. Schoppa, Einfluss der Be- und Verarbeitung auf die magnetischen Eigenschaften von schlussgeglühtem, nichtkornorientiertem Elektroband, Rheinisch-Westfälische Technische Hochschule Aachen, Diss, 2001.

[5] A. Belhadj, P. Baudouin, F. Breban, A. Deffontaine, M. Dewulf, Y. Houbaert, J. Magn. Magn. 
Mater. 256 (2003), p. 20-31.

[6] Y. Senda, M. Ishida, Y. Nakasu, M. Yagi, J. Magn. Magn. Mater. 304 (2006), p. e513-e515.

[7] F. Ossart, E. Hug, O. Hubert, C. Buvat, R. Billardon, IEEE Trans. J. Magn. 36 (2000), p. 3137-3140.

[8] L. Vandenbossche et al, EVS25, Shenzhen, China (2010).

[9] A. Toussaint, Einfluss des Werkzeugverschleißes auf die Teilequalität beim Scherschneiden von Elektroblechen, Technische Universität München, Diss, 2000.

[10] R.M. Bozorth, Ferromagnetism, IEEE Press, John Wiley \& Sons, Inc., Hoboken, New Jersey, 2003.
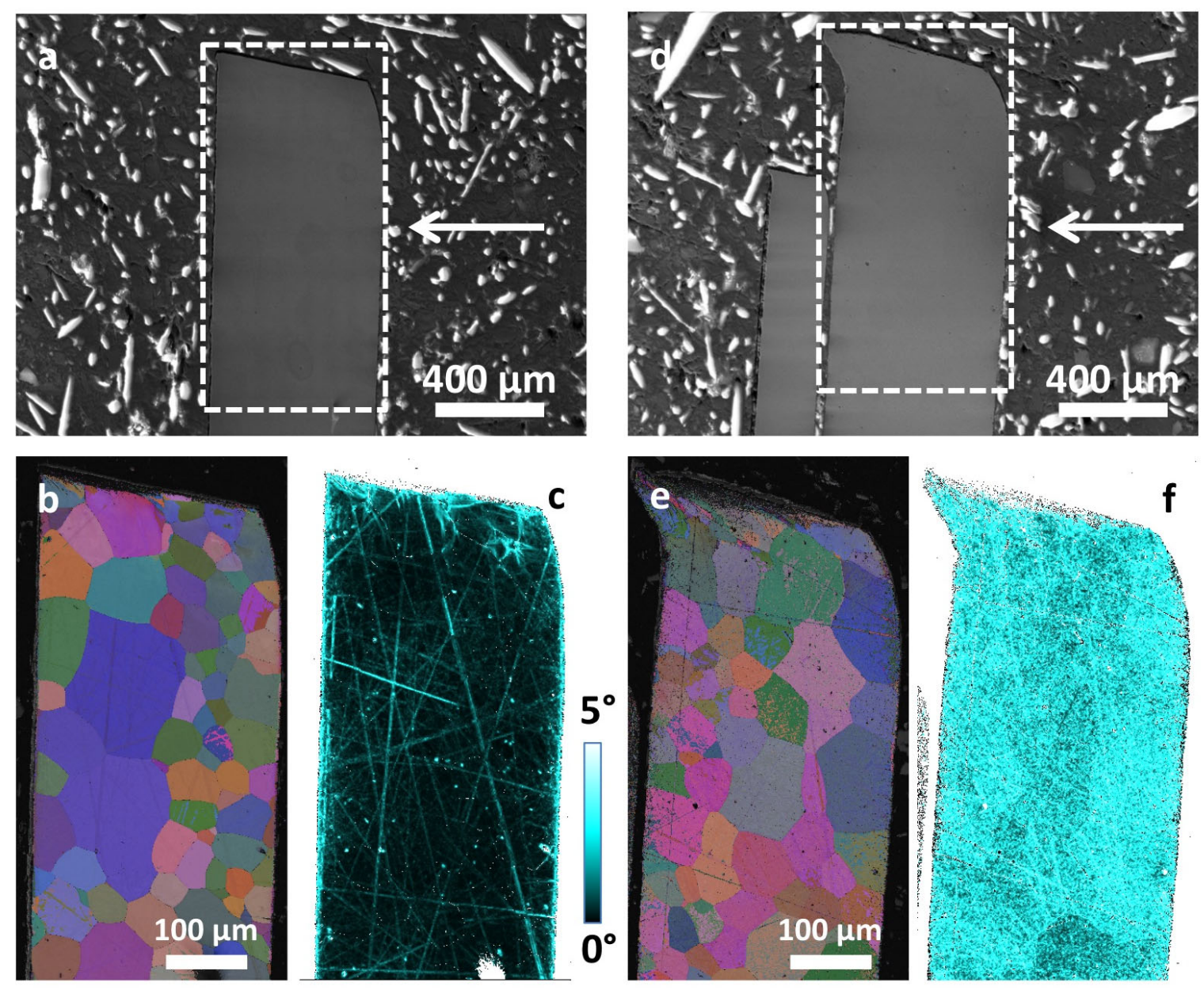

Figure 1 SEM and EBSD investigations of electrical steel sheets cut with a fresh (a - c) and a blunt stamping tool $(\mathrm{d}-\mathrm{f})$ demonstrate the effect of tool wear on the microstructural scale. Already SEM images $(\mathrm{a}, \mathrm{d})$ provide geometric information about the magnitude of deformation by comparing the top cutting edges (arrow $=$ stamping direction). EBSD data of marked rectangular areas $(\mathrm{a}, \mathrm{d})$ are presented in color coded maps of Euler angles $(b, e)$ and local misorientations $(c, f)$ in order to highlight regions of higher deformation. The average local misorientation of the measured areas is below $1^{\circ}$ when using a fresh tool and approximately $3.5^{\circ}$ when using a blunt tool, respectively. 